\title{
Experience Learning on Government Emergency Management of Urban for Typical Developed Countries
}

\author{
Xiang Teng ${ }^{1, a}$, Lei Liü $2, b$ \\ ${ }^{1}$ Basic Teaching and Research Institute, Bohai University, Jinzhou, 121013, China \\ ${ }^{2}$ College of Engineering, Bohai University, Jinzhou, 121013, China \\ ayyq8369@163.com, b674347970@qq.com
}

\begin{abstract}
Keywords: developed country; urban emergency; government emergency management; experience learning; United States; Japan; Russia
\end{abstract}

\begin{abstract}
The government emergency management refers to prevention beforehand, deal with the incident, treatment and rehabilitation management process in emergency, through the establishment of necessary coping mechanism, take a series of necessary measures, to ensure the safety of public lives and property. In the developed countries such as America, Japan and Russia, on the basis of the government emergency management system, summed up the experience and enlightenment for improving the urban emergency management is of great significance. Experience can be used for reference, including: set up specialized emergency management department, the legal system of emergency management, emergency awareness and to develop emergency ability and play an important role of media in emergency management, launch a broad social forces to participate in, give full play to the important role of talent and technology.
\end{abstract}

\section{Introduction}

Strengthening emergency management, is the implementation of the third plenary session of the 18 proposed comprehensively deepen the overall goal of the reform, accelerate the important content of modern management system and management ability. Emergency disposal in our country and the response is still a local government is given priority to, the pattern of other social subject complicit in [1].From the point of the international situation, some developed countries in the long-term practice, for the processing of emergency incidents has a relatively mature and rich experience, and at the same time established a relatively perfect mechanism of emergency management system. Due to different national regime, economy, history and culture and natural environment is different, for emergency management, is a typical model with the United States, Japan and Russia. Research and analysis of the three models, draw lessons from their rich experience in the treatment, is helpful to improve the level of emergency management in our country.

\section{Review on Current Research Situation in Foreign Countries}

Entering the new century, with the development of international economy, especially the rapid development of multinational companies around the world, faced with limited resources and unlimited competition environment, the contemporary western research on government emergency management theory and further development. Research from technology to expand social field and political field, involved in international crisis research, theoretical research, disaster, conflict, and have produced a large number of monographs, representative work of Herman international crisis, graham allison's the essence of the "decision", lewis of the functions of social conflict. At the same time, there has been a fundamental change in terms of research methods, scholars not only from the perspective of history or philosophy, and more attention from the whole system research, aiming at relevant aspects of emergency management research.

Emergency warning, some scholars put beforehand to prevent sudden events and foresee the special important position. Mr Osborne believes that a country like a giant ocean cruise ship, the deck stacked expensive things, there is no crisis early warning as the boat no preventive 
maintenance, no navigation system, no radar, there must be great risk. In the aspect of emergency decision-making, the United States Carnegie Mellon university professor Simon system puts forward the theory of scientific decision for the first time. According to Simon, decision making, it is according to certain goals, research target to the solution of problems encountered are various, by policy makers to use its intelligence, knowledge, experience and judgment, balance the factors of environment and related conditions, chose a best action plan. Promote the decision-making to the core of emergency management position. In terms of emergency information collection, Pearson and milt rove thought spread, collect and analyze information is direct task of crisis management, crisis long originally the first few hours to a few days or crisis, managers should be synchronized to take a series of "identifying facts, loss of control, strengthen communication, depth analysis".

Overall, study abroad is relatively system and further, the purpose is to study the general rules for the government emergency management and how to through the system design and arrangement of operation level, as far as possible to reduce the frequency of the incident, emergency maintenance and promote the social and public interests.

\section{Emergency Management System of American Government}

The government emergency management system is composed of three levels, the federal government and the department of homeland security and resident agencies; State and state emergency management agencies; The local government and local government emergency management center [2].Emergency management system is shown in Fig. 1.

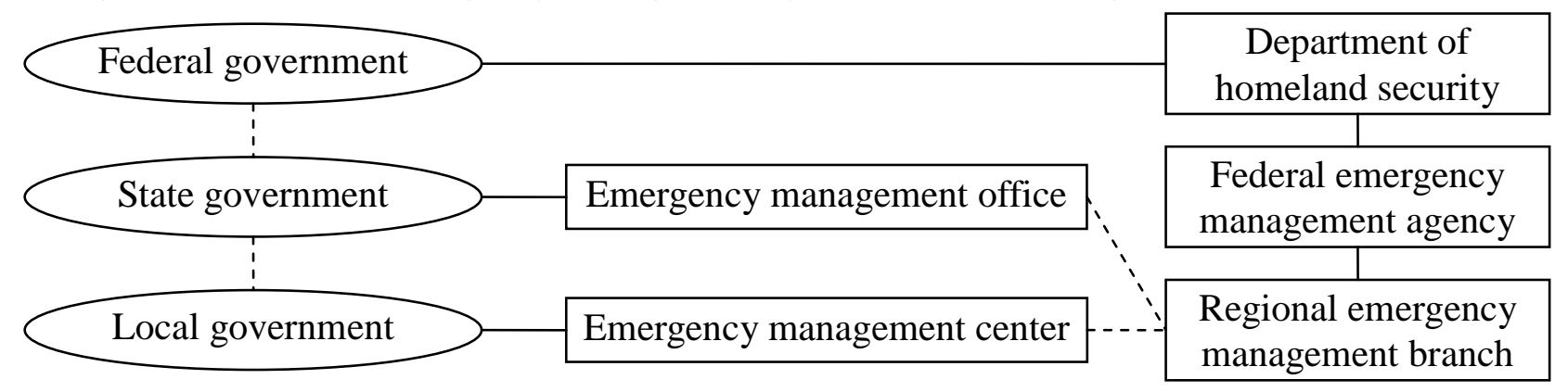

Fig. 1. Emergency management system of American government

The department of homeland security is the highest emergency management agencies in the United States, consists of the federal emergency management agency, main responsibility is through emergency prevention, emergency preparedness, emergency response and post-earthquake recovery and reconstruction, etc. and the whole process of emergency management, leading the country deal with all kinds of disaster, protection facilities, to reduce casualties and property losses. Federal emergency management agency in the United States also has 10 regional branches, is mainly responsible for liaison with local emergency agencies, the rescue plan, collaborative place to organize the implementation of relief, responsible for the assessment of disaster losses.

State emergency management agency, the states has independent emergency management agency, responsible for the disposal of emergencies within their respective jurisdictions. Main responsibility is responsible for handling state crisis event, establish state level of emergency management and disaster mitigation planning, supervise and guide the local emergency services work, organizing the National Guard to carry out emergency operations, and major disasters to the federal government to apply for aid, etc.

Local emergency management agencies, mainly responsible for dealing with jurisdiction within the scope of the crisis event, is responsible for the local level of emergency management and disaster mitigation planning, supervision and guidance work local emergency agencies, major disasters in a timely manner to a state or federal government aid. 


\section{Emergency Management System of Japanese Government}

Due to special geographical location and resources condition of itself, leading to the typhoon, tsunami, volcanic eruptions and earthquakes and other natural disasters, frequent emergencies that Japan has strong sense of crisis. Japan's emergency management system has undergone three stages of development, give priority to with individual land management for disaster prevention and mitigation management stage, from single mined-out area disaster prevention management system to a number of mined-out areas of integrated disaster prevention management system phase, from the comprehensive disaster prevention management system to a national crisis management system. Japan's emergency management system is divided into the central government and village level 3 prefectures, cities and towns, in disasters occur, at all levels to set up a corresponding disaster countermeasures [3]. Emergency management system is shown in Fig. 2.

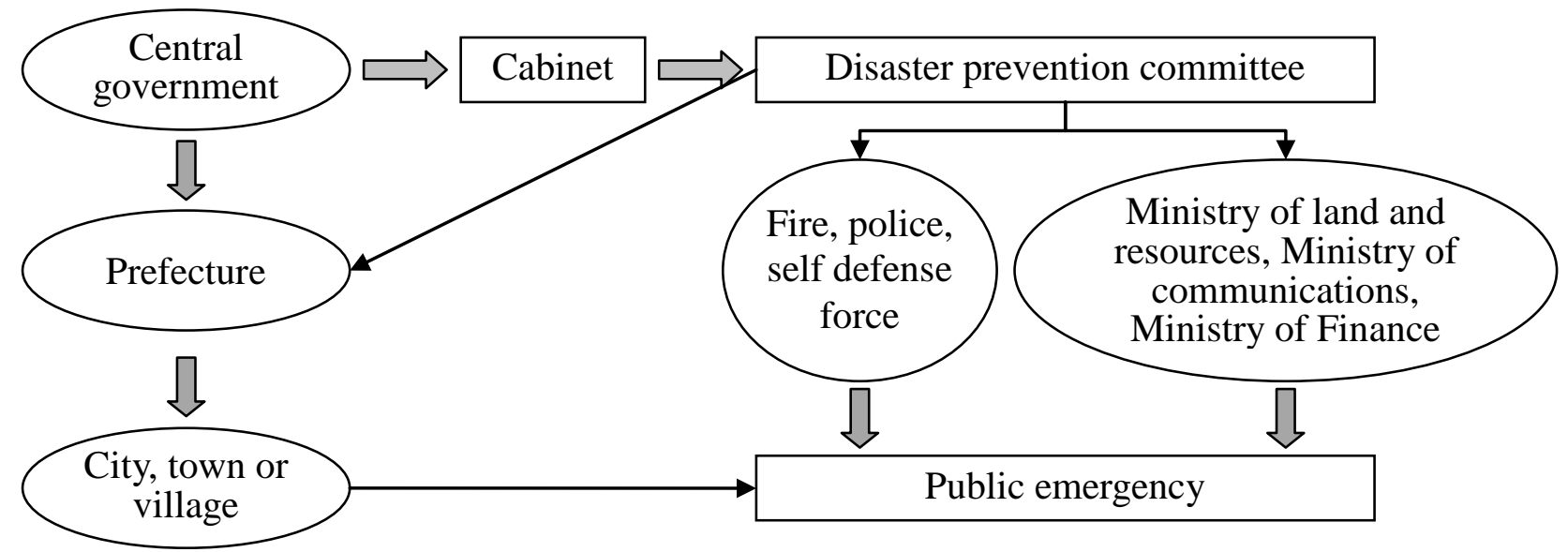

Fig. 2. Emergency management system of Japanese government

Country: country play a role of organization, and take all measures to protect land, people's life and property safety; Formulate disaster prevention, disaster emergency countermeasures and post-disaster reconstruction and so on basic plan, and promote local public organizations and public authorities dealing with matters of disaster prevention, disaster prevention funds for reasonable planning.

Prefectures responsibility: to protect the life and property safety of the people in prefectures area, where authority agencies and other public bodies with the help of these prefectures of disaster prevention plan and implement according to law; Help other area's town village disaster prevention affairs and local public authorities.

The responsibility of the town village: protection of life and property safety of the people in this city county-rural area, in the relevant organs and other local public organizations with the help of this city of county-rural area disaster prevention plan, and based on the law implementation.

\section{Emergency Management System of Russian Government}

After the collapse of the Soviet union, Russia's political structure, great changes have taken place in economy and society, it is in the process of response to the crisis, Russia has formed with the different emergency management system, formed by the President as commander in chief, the federal safety meeting center, emergency management for decision-making support and guarantee system comprehensive coordination of the implementation of full cooperation, various departments and local both division of labor and coordination of the comprehensive emergency management system, as shown in Fig. 3 [4].

Russia's federal system, main is to first determine a decision-making core, namely the President. Here have a full-time President of the national security strategy of important institutions, the federal safety meeting, to control directly by the President. Direct federal safety meeting and some related specialized agencies and 12 permanent supporting institutions. Its specialized agencies is the 
emergency department, emergency department things, related, including the federal security service, the department of defense, foreign intelligence agencies, federal border protection and the relevant functions are in the safety meeting emergency things to deal with department.

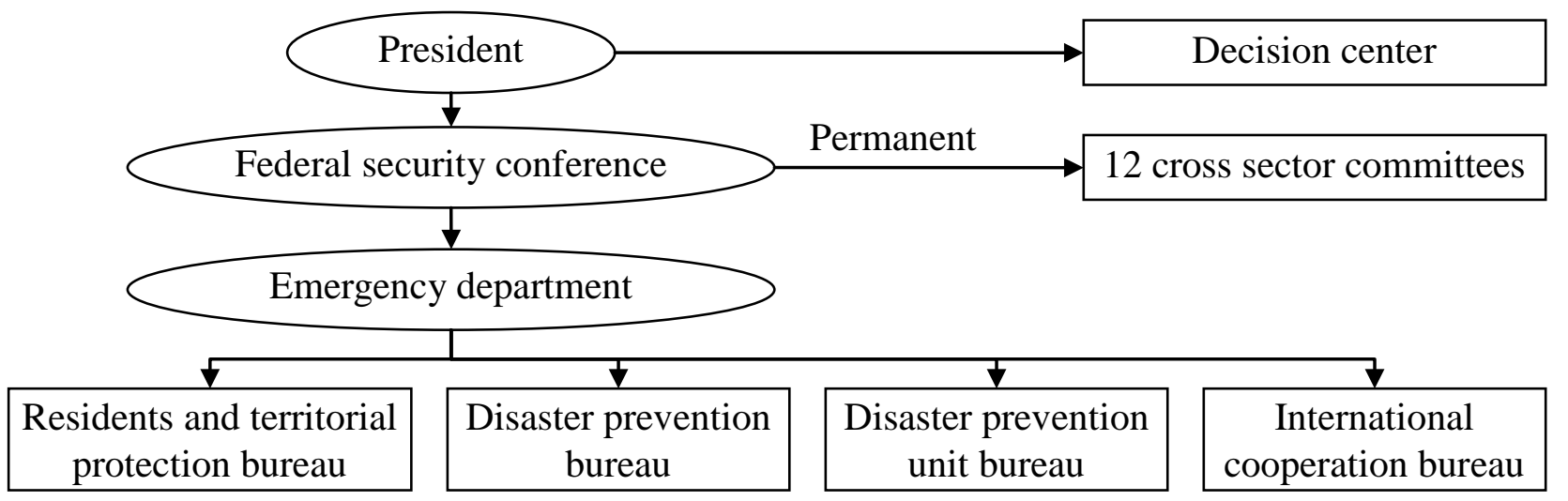

Fig. 3. Emergency management system of Russian government

\section{Experience Learning on Government Emergency Management}

With the unceasing change of international situation and the complicated social structure and the information transmission speed is accelerated, all kinds of emergencies emerge in endlessly, governments are faced with severe challenges. How to effectively deal with emergencies, the risk control to the minimum scope, the world is an urgent need to solve the problem. In these areas, some typical developed countries have established mature experience in crisis management, is worth our learning well and reference [5].

(1) Set up specialized emergency management department. Developed countries attaches great importance to the emergency management of emergency management command and specialized departments. The United States was founded many years ago the federal emergency management committee, the Russian federal security meeting emergency management has become the government public emergency mechanism is an important department. Through the establishment of such a core institutions, in emergencies occur, unified command, unified standard, the coordination of other related emergency department, reduce the harm done by the public emergency, win precious time for emergency response. Set up specialized emergency management department has the following several kinds of mode, the federal emergency management agency, Russian emergency ministry and Japan's Kyoto disaster prevention center mode. In either model, is a specialized in the crisis management of government agencies as the core. Specialization of public crisis management and public crisis management organization specialized closely together, workers have a particular aspect of technology or expertise.

(2) The legal system of emergency management. Developed countries attach great importance to the emergency management of the construction of laws, regulations and policies. Have relatively perfect laws and regulations system, realize the national emergency management legalization, the emergency management mechanism of internal institutions responsibilities clear, reasonable division of labor, efficient operation. In accordance with the law to deal with all kinds of public emergency, to reduce casualties and property losses in emergency, as soon as possible to restore normal social order is of great significance. Emergency management legalization, can ensure that governments and institutions on effective exercise of emergency power, emergency and emergency laws.

(3) Improve the emergency consciousness and train the ability of emergency. In emergency consciousness and the ability of emergency education and training, every country attaches great importance to the German government's "crisis prevention information system" main duty is to provide people with critical cases of self-preservation and save your knowledge, also in the form of exhibitions and publicity introduced all kinds of emergencies and its response to the public. Publicity week and awareness month, the Japanese government has disasters during the activity in 
the form of simulation experience, speech and media publicity and emergency protection and save your knowledge, to make people know escape essentials and first aid. Media such as the United States government in addition to using the Internet and telephone to provide public emergency information, also by printing the emergency instruction to improve the emergency of public awareness and level.

(4) Play an important role of media in emergency management. In the process of emergency disposal, developed countries pay attention to establish good relations of cooperation with the media to make media publicity of government decision-making way and public access to information channels, right in the bridge to build a good interaction between the government and the public. Some countries and even the media as the main body part of the government crisis management, plays the important role of the government crisis information spokesperson ", known as the "shaper" image of the government crisis management. British attaches great importance to the collaboration between the government and media in emergencies, be included in the content of the emergency response plan, appointed specially trained news officials responsible for media affairs, even ask the switchboard operator and other staff members to learn how to communicate with media.

(5) Launch a broad social forces to participate in. Government is the main part of the emergency disposal sector, but because of financial investment, personnel expenses and organization distribution, as well as inadequacy, reduces the disposal efficiency, influence the treatment effect. Therefore, the government departments should jointly social forces and private organization, jointly cope with emergencies. America through publicity measures to education of civil organizations, develop effective strategies to joint social forces, attract private human resources. The participation of social force, on the one hand, is beneficial to reduce the cost of the government for public management, on the other hand, is conducive to give full play to the role of the social forces and private organizations.

(6) Give full play to the important role of talent and technology. Developed countries have more expertise and equipment, professional technology, advanced information communication mechanisms, has also established emergency management personnel training system, rescue personnel training and assessment system. Russia's crisis control information center, automatically collect information analysis system, command system and 24-hour duty system, can realize complete coverage of information, 2 minutes in each village and settlement established feedback system. Focus on high-tech research and professional talent training, strengthening the construction of emergency management information platform, establishing responsive powerful information reporting system, in order to avoid and reduce the loss.

\section{Conclusion}

With the unceasing change of international situation with complicated social structure and the information transmission speed speeding up, all kinds of emergencies emerge in endlessly, governments are faced with severe challenges. How to effectively deal with emergencies, the risk control to the minimum scope, the world is an urgent need to solve the problem. From the study to the President as the core of emergency management, federal safety meeting decision of Russia's emergency management and comprehensive treatment of three emergency management in developed countries such as Japan emergency management, on the basis of summed up the emergency government emergency management experience of developed countries and enlightenment, emergency government to improve the city emergency management ability plays an important role.

\section{Acknowledgement}

This work is supported by 2014 annual social science planning fund project of Liaoning province (L14DGL043): Improving to countermeasures on urban emergency government emergency management capacity. 


\section{References}

[1] H. M. Cao, W. N. Huang, "Research on the Evaluation Index System of Local Government Emergency Management Capabilities," Journal of Guangzhou University (Social Science Edition), vol. 14, no. 12, pp. 60-66, 2015.

[2] Baidu Wenku, "Emergency management system in the United States," http://wenku.baidu.com/link?url=SjdzvOKSqDAJEybOoDWpqAAlNbwng2MyIm9GdehTKii1 BQOBi5DuwN0eqNKF_Cdx0KuicDxTnZaG0eooJ-ZjLd-jUE4uKkz6MRwkKr_zMlK, 2016-4-20.

[3] Baidu Wenku, "Analysis of emergency management system of public emergencies in Japan," http://wenku.baidu.com/link?url=c9wIjmm3N8jiIcNSa9jS3SP59WJRPJwAbb0U2-j3ecosvKE W2zXbzQb34qh4nw-LSif55Z24umC_Vfp2SP1KO-zWAj1aKleOCsPL_rvDb3G, 2016-4-20.

[4] Baidu Wenku, "The emergency management system in Russia and Its Inspiration to China," http://wenku.baidu.com/link?url=SyQ43TgDsEPEG9NrpkhmL26F56CfujujJkdbXMkiw9uAM JquMmxQl9u4r_yvAp20xkFYGvzIJYBRj81vwKGfAD7_R00Q10_kIV9HODgmljm, 2016-4-20.

[5] W. L. Hu, "Research on emergency management system of Chinese city sudden public security incidents," Master's degree of Wuhan Institute of Technology, 2013.

[6] X. M. Liu, "Study of Modern Emergency Management," Master's degree of Wuhan University of Science and Technology, 2013.

[7] Z. S. Zhang, "Research on emergency management mechanism in Hebei Province," Master's degree of Yanshan University, 2013. 